\title{
American dream, Humboldtian nightmare: Reflections on the remodelled values of a neoliberalized academia
}

\author{
Ana Tomicic \\ La Sapienza University of Rome, Italy
}

\begin{abstract}
While universities now lie between two philosophical poles - idealism and utilitarianism - the Humboldtian ideal primarily serves to give a humanist glaze to a technocratic discourse. Regardless of its autonomy on paper, the University does not control its finances. This guise of autonomy has set a double authoritarian heteronomy of the university: from increased administrative supervision and from market control. While the current debate is strongly permeated by the idea that we should simultaneously compete with and copy the model of elite US universities, this article presents reflections on how detached from Humboldtian ideals we now are, explores the consequences of that transformational logic and encourages debate through critical distance.
\end{abstract}

Keywords

Higher education, research, audit, reforms, neoliberalization, Bologna system

\section{Introduction}

The central concern of this article will be to ask how the pursuit of neoliberal, market-driven goals by state-run institutions undermines the goals of universities inspired by the ideals of Humboldt and Newman found throughout Europe, and short-changes the students and communities who have invested their time and resources into furthering those ideals such as exploring knowledge for the sake of knowledge, seeking truth, transmitting knowledge and serving society. While this article draws on the rich research done on the state of the modern neoliberal university, it focuses on a critique of the influence of the market-driven discourse. This paper will highlight the divergent goals of autonomy on the part of the university, the protection of academic freedom on the part of individual researcher teachers, and the rising audit culture. In this sense, this article seeks to present a fuller critique of the influence of neoliberal thinking than some of the other models for doing this work, such as Sosteric et al. (1998), Krajina and Krajina (2014), or Sorensen et al. (2016). Their work tended to focus on one aspect at a time, rather than the broader cultural shifts that have brought about a transformation from Humboldtian ideals to neoliberal, competitive institutions. Furthermore, this paper considers the threat posed by the US, Canadian and Australian university models that have wholeheartedly adopted the logic of the market and weaponized it against their European competitors. The results of the growth of the neoliberal, market-driven university model are visible in the stifling of scholarly creativity and curiosity, the corrosion of scholarly relationships through competition and competition-related anxiety, and the publication of a lot of uninspiring and mediocre research in what once was society's strongest engine of innovation. The ultimate result is a concept of the university that not only has been transformed from its original ideals, but also has critically damaged its own potential future.

Two idealistic conceptions of the university dominated European thinking in the 19th and 20th centuries. The first was developed in what is now Germany by Wilhelm von Humboldt in the early 19th century. Humboldt attached great importance to the prefix uni in the word 'university'. To him it meant universal in the sense of including all. In other words Humboldt regarded knowledge as a single, integrated system and the essence of his model is a holistic academic education based on humanist principles which sought to cultivate the minds and characters of students. The Humboldtian ideal embraced not just the preservation of knowledge or the training of professional skills, but rather a search for truth that embraced curiosity, creativity and passion. The ideal Humboldtian institution was a 'community of scholars and students engaged on a common task'. Humboldtian universities gave equal importance to both arts and sciences and combined both research and 
teaching. Teaching should be guided by impartial research based on a quest for the truth driven by reason. The aim was to promote self-education; students could choose their own curriculum in contrast to the prescriptive French system. But they should do so with an awareness of being part of a world which carves them and one they have a duty to shape students of the Humboldtian university were meant to become true world citizens. Although Humboldt believed in absolute academic freedom, he also conceded limits to autonomy and a substantial role for government in establishing and funding an education system. As a result of his connections with the Prussian monarchy and government, Humboldt's model became the basis of German liberal education in the 19th and early 20th centuries and spread to eastern, central and northern parts of Europe (Anderson, 2010a).

However, Humboldt's vision of a university was not the only idealistic model. The English theologian John Henry Newman also developed an ideal of a university. Newman also believed that knowledge was a whole and drew on Humboldt's ideas in other respects also. But their visions differed in several significant respects. Newman's focus was less on research and more on the dissemination of knowledge through teaching in order to benefit society under the law of God which he believed was the source of the unity of knowledge. His approach to the curriculum was also different in that he did not really abandon the medieval trivium and quadrivium with its emphasis on the classics and on theology. In Newman's The Idea of a University (1845) science is almost an afterthought grafted uneasily onto medieval roots and the purpose of his book was to justify the decision of the Papacy to found a Catholic university. Nevertheless, his model had, and still has, considerable influence in the English-speaking world.

Advocates of Humboldt's and Newman's models did not seek to destroy each other and in some countries both approaches have been implemented side by side. For example, in the UK, Russell Group universities focus on a Humboldtian approach combining research and teaching across a broad range of faculties while the Post 92 Group of former polytechnics concentrate on the dissemination of specialist, often scientific and technical, knowledge through a teaching led approach. A similar pattern can be observed in France where Les Grandes E' coles follow a Humboldtian ideal of holistically educating the minds of a leadership elite while the more utilitarian Lyce'es d'enseignement focus on disseminating skills for employment.

This article focuses primarily on the institutions affected by the Bologna Process initiated by the EU wherein universities from 48 European states, in the EU and beyond, which have come together through the mechanism of the European Higher Education Area (EHEA) and European Universities Association (EUA) to facilitate the mobility of students and faculty between countries, harmonize qualifications, provide quality assurance and impose a common management system driven by performance indicators (European Commission, 2019). Academics have shown widespread awareness of the contrasts between the Humboldtian tradition and the EHEA effort, known as the Bologna Process. For example, Serrano-Velarde and Stensaker (2010) have contrasted different meanings attached to 'quality' while the introduction of a separation of funding for teaching and research has been seen as a fundamental break with Humboldtian principles (Fr_lich et al., 2010). In some quarters the Bologna Process has been greeted with dismay and there has been a concerted attempt to defend and market German, Humboldtian institutions internationally (KAIM, 2000) supported by eminent philosophers such as Ju“ rgen Habermas and Julian Nida-Ru“ melin.

This article will support that defence and reassertion of Humboldtian core values and argue that they remain essential to the true role of universities in the long term.

The source of recent attacks on the ideals of both Humboldt and Newman is a new neoliberal paradigm of the university. In the neoliberal model, providing graduates with career prospects as dictated by the free market economy has become the central priority. Some parts of the Humboldtian model remain. For instance, in the neoliberal model, students can still choose their studies based on their tastes and the curriculum is still expected to contribute to their self-actualization. But, especially in the US university, which is often considered a highly desirable model in Europe, students are guided towards courses according to the prospects of professional success that they offer (Alain, 1995). Humboldt held that fundamental research was vital for its own sake and for its capacity to train the mind but, if it remains crucial in the neoliberal model, it is only because it is a prerequisite for implementing the technical sciences and subordinate to its ability to be monetized. Industrial development also entails new requirements for the training of cadres: as the administrative and economic political sciences have become indispensable 
aids to progress and have made strong headway into universities' programmes, at the expense of entire departments of humanities which are closing their doors, arguably as a result of changes in the patterns of women's enrolment as they seek to take their place in the technological and managerial workforce (Tworek, 2013). Simultaneously, research parameters are now defined by the neoliberal universities' increasing dependence on external funding sources separated from teaching and aimed at revenue generation while students are seen as customers buying a utilitarian qualification rather than seeking a holistic experience. This new model emphasizes economic efficiency in the running of universities with a particular focus on the dismantling of the tenure system (Saunders, 2010).

University policy makers are presently torn between two conflicting poles, which define their course of action regardless of the philosophical history and previous research or teaching focus of their institution: Humboldtian idealism or neoliberal utilitarianism. In the UK it has been argued that regardless of a university's autonomy on paper, universities no longer have the collegiate nature stressed by Humboldt and taken for granted by Newman with his experience of Oxford. A university no longer controls the financial means of its management which has become increasingly corporate and hierarchical in nature as well as subject to externally imposed 'reforms'. Autonomy seems to have been replaced by heteronomy (Finlayson and Hayward, n.d.). Much the same trend can be observed in France, for example - the Pe'cresse law preconizes autonomy but contradicts itself: there is less pedagogical power for teachers, more bureaucratic and administrative power, and more dependence on private funding and market dictates. A decade ago, the French ARESES (Association of Reflection on Higher Education and Research) denounced the confusion between competitive autonomy and academic freedom.

The invocation of the autonomy of universities has now become an administrative weapon to justify the global disengagement of the State and in order to divide the competing establishments from one another with regard to the distribution of financial resources (Charle and Soulie' , 2007: $8-9$, my translation).

European universities have begun to realize that changes in science and society can take place without them, and that European higher education institutions (HEIs) are competing with private institutions such as think tanks and corporate Research\&Development centres or foreign universities, particularly US ones. But it is unfair competition as elite US universities have a different level of financial resources available to them. The University of Wu€rzburg in Germany, for instance, which is comparable to Harvard in terms of its enrolment, only has the fourth of Harvard's annual budget. A similar disproportionality appears among the professors: 400 professors for Wu€rzburg and 2700 for Harvard. Obviously, European HEIs cannot be expected to perform as well as the Ivy League universities in the United States unless their financial resources are significantly increased. On the other hand, the network of high-quality European universities is richer and more varied than that of the USA (Berchem, 2004).

Here, it is important to note that the EHEA reforms have been suggested because the perceived need to compete with neoliberal US universities has resulted in a reform of the institution that has emphasized competition. The suggested organization of the university - and the scholars, institutions and programmes within it - is one that creates a Darwinian context of competition and 'struggle for life'. This model, drawn insidiously from private sector firms and promoted in the name of being competitive in the knowledge economy, has elevated competition to the rank of virtue, often at the expense of creativity, curiosity and collaboration, to suit the requirements of a neoliberal conception of a free market society where everything, starting with science, is potentially marketable and can generate profit.

\section{Autonomy served in Bolognese sauce}

One key element of neoliberal reform is the rising concern regarding financial autonomy for the university, which stems from the broader nature of the economic construction of Europe that began in the 1950s. Humboldt did not deny governments a role in the financing and administration of universities. Most modern European universities do not have the historical, religious endowments that Newman assumed and the US Ivy League universities actually have. Nevertheless, reflecting on how far removed from Humboldtian ideals we are 
now, Rosalind Pritchard claims that

the real question is how far the response to economic demands should be driven by priorities determined outside universities, rather than by curiosity, originality and the internal development of disciplines. A knowledge economy depends on the quality and independence of the knowledge, and intellect can only be a creative force when it is free. Thus, this question involves classic issues of academic freedom and autonomy (Pritchard, 2004).

It also involves investigating the insinuation of the managerial discourse that has already marked the transformation of other public services into the logic of the university on every institutional level.

In the early 1950s, the construction of Europe was already conceived as a strictly economic affair (Gelauff et al., 2008) and this included the gradual integration of educational policies into the agenda of the European institutions. In short, educational reform as enacted in the Bologna Declaration (1999) was not designed to contradict, or even to nuance the economic nature of Europe's construction, but to complete it. Homogeneity, as encouraged by the Bologna process, is a condition of capitalism that is necessary for value to be comparable. To achieve homogeneity, universities undergo the same transformational logic that led to the reform of public services according to business management principles and discourse (Sosteric et al., 1998). The neoliberal paradigm of knowledge seems to systematically reduce education and training to issues of employment. By making mass unemployment the product of purely individual deficits of 'employability', the European Commission has managed to weigh on the educational reforms successively implemented by the Member States. Knowledge is thus reduced to its short-term market value by this narrow, utilitarian conception that is comparable to the kind of thinking used to improve the competitiveness of firms. Their view of the short-term risk - the teaching of immediately applicable knowledge - does not account for university training's long-term value, as emphasized by Humboldt, which consists in empowering graduates to cope with new challenges that did not exist at the time of their studies. This short-term focus on the immediate employability of graduates can prove to be very costly in the long run, since it does not consider the need to anticipate progress and neglects opportunities for lifelong learning. Thus, as the European Round Table of Industrialists (ERT), the most powerful business lobby at European level, argued in one of its reports, 'Education must be made an open, interconnected chain of learning opportunities available to people from cradle to grave' (Sosteric et al., 1998; Cochinaux and de Woot, 1995: 1), meaning that 'governments should encourage the workforce to expand their skills throughout their whole lifetime in order to create more profit for business owners'. The ERT added that 'the only valid alternative for Europe to survive and remain competitive in world markets lies in a strong capacity for innovation and quality. This can only be achieved with a highly and broadly skilled workforce' (Cochinaux and de Woot, 1995: 12). The ERT also argue that this approach reduces education to a purely individual imperative - increasing one's own 'employability' by accumulating 'human capital'. The concept of 'human capital', which was introduced into economics in the 1960s by Gary Becker, constantly re-emerges in the prescriptions of the European Commission and is associated with the apparently legitimate requirement of 'lifelong learning'. This essentially mystifying concept attributes mass unemployment to the unemployed individuals themselves, rather than to their employers' policies or to macroeconomic imbalances linked to the structural contradictions of capitalism. At the same time, this concept is also squeezing out the question of capitalist exploitation. Indeed, each employee is forced to renew and increase his stock of 'human capital' in order to improve his position in an increasingly 'flexible' labour market. In this model, the employee becomes the 'entrepreneur' of their 'skills', much like the capitalist who manages their assets. Here, we see how reforms presented in the joyful light of student mobility, of the 'cognitive society' or of 'lifelong education' are in fact supported by a vision of humankind that is defined, in principle, by the needs of capital.

European universities have always evolved but for most of their history slowly and cautiously in part because of their collegiality and the need to find consensus and in part because of the sense of security created by their dependence on state funding and insulation from competitive pressures. On the other hand, in recent years the private company has come to be seen as an ever more dynamic and flexible structure, able to adapt its organization and its goals to the requirements of a changing socio-economic reality. However, the priorities of the university are not those of the private company. The commonality of 
interests built around the same representation of 'useful science' is only apparent because this utility of science does not hold the same meaning for all. Where the university would expect that knowledge serves both humankind and the economy, the private company would expect that knowledge serves humankind through the economy. There are different mechanisms controlling how universities and companies serve society and different conceptions of the purpose of doing so. Humboldt believed that the purpose was to train the minds of leaders and instil culture. Newman believed that universities acted in the service of God. Most modern universities would argue that the purpose of their expansion of knowledge is to solve social or scientific problems and they do so via the mechanisms of influencing public opinion and state institutions. Neoliberal capitalists, by contrast, argue that companies use knowledge to satisfy human needs at a profit and do so by interacting with consumers either through a supply chain or directly. These are very different conceptions of the purpose of knowledge and the method of doing so. But a growing integration of higher education into the global capitalist system fails to recognize this and is reconfiguring that system of education in ways which may have unintended and troubling consequences.

\section{The governance of the university - Antigone's death}

The new spirit of capitalism has some troubling consequences for individuals and institutions; much like Antigone, who only attained the autonomy she sought in death, individuals and institutions operating under neoliberal logic can only survive and can only preserve even a pretence of their own autonomy by abandoning their core essence and freedom - a kind of institutional death.

The freedom of research is only really guaranteed when universities have sufficient equipment and finances. If the only available financial resources depend on commercial vested interests, the freedom of science is only a theory. So, paradoxically when the Humboldtian university was funded by the government it actually had more autonomy than under the neoliberal model. The university's autonomy did not guarantee its own freedom; rather, it serves to guarantee the academic freedom of teacher-researchers because they had the freedom to decide their research agenda and the resources to deliver it. In the neoliberal paradigm, on the other hand, when universities have to compete for resources with each other, and with rival research hubs such as think tanks, universities have 'autonomy' but they are actually forced by market forces to focus on the research that corporate investors are willing to fund. This is why it is necessary to question whether the new autonomy's keywords competition, profiling and efficiency - maintain the aims of science or whether they present a potential danger for research. From this perspective, neoliberalism can be said to be an evolution towards a paradoxical type of governmentality: the apparent withdrawal of the state marks in reality an even stronger but displaced interventionism. Neoliberalism, therefore, will not be placed under the sign of laissez-faire, but on the contrary, under the sign of vigilance and permanent intervention. The alternative to this dependence would be to push the logic of financial autonomy to its limits, which would mean trading one dependency for another, echoing Antigone's autonomy found only in death. Rather, it is a question of establishing a sort of dual power and legitimacy within the institution: to refuse to allow the state to interfere with what does not concern it and to encroach on pedagogical autonomy; and to open up, on the other hand, to all those concerned, to students and staff as well as to all possible actors outside the academic tower. What is at stake is nothing less than the issue of whether knowledge and education are common goods of mankind or whether they must become commodities like all others - is the university an inalienable part of the public space, or a production enterprise subject to the 'knowledge economy'.

This financial logic, the theory goes, will lead to the development of instruments and mechanisms of rationalization that will make institutions more autonomous and less costly for the collective (through a rationalization of management with new information technologies, an individualization of tenure statuses, a redefinition of functions, an increase in the number of non-permanent staff and a setting-up of evaluation measures) (Gueissaz, 1999). Essentially, institutions are competing at the same time that student mobility is increasing, because of the opening of European borders and the harmonization of university policies. The texts of the European University Association (EUA) provide a key for identifying this dominant discourse because of the central role the EUA plays in the harmonization of university policies in the countries of the European Union. Its partners, among others, are the members of the Round Table of European Industrialists (ERT) and the American 
Council on Education (ACE). There are two goals for evaluating universities that are central to the EUA's broader agenda. First, the EUA seeks to assess European academia using quality assurance (QA) and (global) rankings. QA 'is intended to guarantee compliance with (minimum) standards and to support quality enhancement'. It is mainly focused on the teaching role of universities. Meanwhile rankings are intended to 'identify excellence' but also have an, often unstated, commercial purpose of attracting private sector research funding. They are therefore mainly based on research performance which or may not be aligned with teaching performance (European Parliament, 2015). The aim is to impose standardized, normative matrices for evaluating performance and providing quality assurance such as the European Standards and Guidelines for Quality Assurance (ESG). Second, the EUA wants to use the shortcomings it identifies to form a basis for recommendations for reorganizing universities to follow specific objectives. This has involved three tiers focusing first on bachelor degrees, then masters and most recently doctoral level courses (European Commission, 2019. In essence, this evaluative process's long-term goal is to standardize universities into one single, neoliberal model. Basically, the EUA follows the working model of big private auditing companies, drawing its legitimacy from its expertise and its apparent independence.

Strategy, management, competition and adjustments are all concepts that connote the influence of managerial literature and are a leitmotiv in the documents of the EUA. They assume that the university will find the resources to adapt to an environment that is determined by the economy by patterning its functions on those of a private firm serving its paying customers. Hence these evaluations question the entire traditional dimension of the university's role in society as understood by Humboldt and Newman. This transformation's underlying logic is strictly pragmatic, and universities are attempting to render this logic more acceptable by emphasizing the moral arguments, principally that the reforms provide better value for students in terms of more contact hours, better campus facilities and higher employability at less cost to the taxpayer. However, Wilson (2012) argues that the appearance of empowering students by treating them as customers is false because it leads to a culture of credit accumulation and the erosion of free speech by providing an incentive for lecturers to avoid challenging content for fear of alienating paying customers. It can, therefore, be argued that universities are no longer fulfilling Humboldt's vision of their role in society as impartial and fearless seekers after truth.

Finally, under the EUA regime, the university has adopted the notion of becoming a 'learning organization' able to adapt to the changing circumstances that are constantly faced by the individual and the collective. Universities have been forced to seek competitive advantage based on their ability to continuously re-formulate the objectives of any activity, in matters of general management as well as of research. That must privilege the centres of excellence, especially in terms of possible research revenues for the institution, and of meeting the needs of external economic partners. It also leads to teaching designed in order to meet the short-term requirements of the flexible labour market at the expense of the Humboldtian, longer-term approach to holistic education of the mind.

Debates about the management of higher education in Europe, such as the OECD monograph, have been influenced by contributions from US, Canadian and Australian academics.

But European voices are also urging a more economic conception of the role of universities. For example, in some circles, universities are now perceived to play a role in international trade. In 2002, the reporter for the US/OECD Forum on the 'Trade in Educational Services' noted that there was 'no doubt that trade in educational services is not just an incidental spinoff of programmes to enrich education with international exchange but has also become a significant part of world services trade' (Hirsch, 2002: 6). Employers have voiced their demands as well. In 2006, the Education and Training Report of UNICE (Union of Industrial and Employer Confederations of Europe) suggested 'Developing lifelong learning remains an essential priority if Europe is to become the most competitive knowledge-based economy and society in the world' (ETUC et al., 2006: 11). Finally, in 2007, the European Economic and Social Committee described employers' demands for education.

Much need exists within the EU for changes in the education and training curricula - in particular on the level of higher education - to place more emphasis on advanced entrepreneurship education, the strategic value of information management and ICT and networking. The role of schools and universities is an essential factor in fostering an entrepreneurial mind-set among young people. Active participation of company representatives in education, for example, is recommended as well as an involvement from business organisations (European Economic and 
These examples show how the increasing role of economists and employers as active and vocal stakeholders in higher education has reduced the traditional autonomy of the university to seek its own path to discovering truth.

Government reformers have skilfully attempted to present the law on autonomy as higher education's emancipation from the traditional tutelage of a centralizing Jacobin State.

However, the academic freedom of those who teach - and their students - should not be confused with autonomy. There can be autonomy without freedom, and freedom without autonomy. Research must be largely independent from the state or interest groups; it should serve only its own cause, especially so-called 'blue sky' research which seeks to understand something in nature, such as subatomic particles or the origins of the universe without yet seeing its practical applications or marketability. Thus, autonomy means that researchers and teachers make decisions about the subjects, themes and methods they study. However, it does not mean that there are no boundaries. When they are teaching and researching, individual academics and institutions must respect the international standards of the scientific community regarding ethics and integrity. There can be instances when the objectives and methods of research come against the limits of ethical and moral principles and scientific autonomy has to be restricted. Human embryo research is one topical example. The point is that in the Humboldtian model the boundaries were set by the academic communities themselves. But in the neoliberal model external stakeholders motivated by economic imperatives are imposing new and very real dangers to the freedom of research through financial restrictions and competitive pressures to produce measurable returns on research investment rather than moral considerations.

\section{Criticism and acceptance of the neoliberal paradigm of the university}

It is important not to oversimplify matters by opposing 'the new corrupted university' to an old 'ideal university'. Things are never that simple. But it is difficult not to be surprised by the university's passivity when confronted by external dictates intended to direct its corrupted evolution. As much as this ideology benefited from a political, mediatic and institutional recognition, the 'silence of the labs' is deafening. Just as the New Spirit of Capitalism flourishes in the absence of a consistent critique, this change in the university does not seem to meet any real opposition. For example, in the UK, the tripling of tuition fees in an attempt to remove subsidies for traditional universities and thereby reduce barriers to entry to new, private sector HEIs was met with very limited opposition from students and compliance from existing universities much to the dismay of isolated voices on the political left (Choat, 2017). This may be explained by the fragmentation of the university that encourages individual action over collective action. As Choat (2017) puts it,

The introduction of fees has been a vital factor in the acceptance of neoliberalism in universities, especially among students. Fees have changed the way that many students view their education, making them far more instrumental, focused purely on the end result - a degree and the higher earning potential it brings - rather than the process of learning. What fees have produced is not so much the 'student consumer' as the 'student entrepreneur': a degree is not so much a product as an investment that is made with the anticipation of a future (financial) return.

One paradox of the university when it followed the models of Humboldt or Newman was that it was rarely its own object of research and the university rarely felt the need to publicly defend itself. But the transformation of the last 20 years has attracted enormous attention within academia as the number of articles cited in this paper goes to show. Sociologists, anthropologists and philosophers have all opposed the neoliberal paradigm from various standpoints. The problem is that their publications are hardly echoed in the press or anywhere outside the institution itself. They receive little media attention, except from the part of ideologically engaged media, often qualified as 'leftist' and/or 'idealistic', with therefore little credibility to many academics and policy makers. Academic critics of neoliberalism have certainly not succeeded in reversing the trend in Europe or further afield.

Although the Humboldtian ideal of the university may sometimes suggest otherwise, there is no self-sustaining ideology. To exist, ideology needs not only justification but also 
a means of dissemination. Universities often emphasize exceptional and spectacular research results and boosting has become part of the armoury of the 'ideal' academic to the detriment of gender equality and those who fail to meet the new quality standards. Institutions focused on linguistics, philosophy or history are also suffering; although prospective students, especially women, are showing less interest in these topics anyway

(Tworek, 2013). However, those promoting any university ardently highlight its geographical and cultural assets to attract students in an increasingly competitive marketplace where students who were once described as the 'future of the nation' are now implicitly considered the 'future of the budgetary balance of the university'. Universities will try to highlight the 'secondary benefits' that they can offer to 'their customers' over their 'basic products': guidance, assistance in the preparation of exams, supervision and so on. More often, universities will promote the institution's competitive capabilities by citing their place in rankings despite their well-documented methodological deficiencies (European Parliament, 2015; Samarasekera, 2007). In this new model, universities are judged not only on the results of their activities, but also on the image they construct while implementing this programme.

Indeed, the neoliberal university implements a planned and conscious strategy of seeking recognition by complying with a standard that has been defined by neoliberal values (Goffman, 2009). Administrators, teachers, researchers and students are supposed to always act in a spirit of efficiency and competitiveness, producing work better and faster than their competitors, aiming for more subsidies, new contracts, a 'better' diploma - in short, trying to survive until someone better than oneself gets the longer end of the stick. Individual academics go along with this process, either subconsciously because in this on-going struggle, there is hardly room for soul searching, or simply to survive in a climate where the cancellation and disappearance of tenure track positions and research chairs is another major concern of academics.

In North American critical literature (Ray, 1997; Readings, 1996; Samarasekera, 2007), the links between academia and the economy are examined, and, as a corollary, scholars have engaged with the implications of capitalism contingent on the organization and functioning of the university. This system is consistently rationalized by the tendency to prioritize the tool, the method or the organization over the content. Albert Jacquard, the French popularizer of science, has drawn clear attention to the disarming evidence of neoliberal thinking, blinded by its compulsion for accumulation - there can be no winners without losers, and that there are always many more losers than winners. Is the marketoriented university, supposedly so concerned with humanism, aware that it contributes much more to the creation of a society of the excluded than to the democratization of knowledge? Several scholars have drawn attention to issues of gender equality raised by an ever more competitive environment (Lund, 2018; Tworek, 2013). Others have highlighted the exclusion of lifelong learners by the imposition of tuition fees (Choat, 2017). Furthermore, those who believe that neoliberal economics lead to social exclusion have extended that argument to conclude that the use of university rankings channels funding to elite, global institutions and acts as a new channel of social exclusion (Amsler and Bolsmann, 2012). This is an interesting paradox at a time when governments, particularly in the UK, are putting pressure on universities to reach out to a more diverse student population.

\section{A changing university culture: Audit, precarity and the meaning of 'excellence'}

The university does not escape the assessment fad that now affects anything that can be considered a business, including public administration and, especially, educational institutions, which have now been transformed into training institutions for employees and entrepreneurs, commissioned by the market. This practice, also borrowing from 'quality management', is longstanding and customary primarily in North America from where it has recently been adopted by several countries in Central and Eastern Europe. If a university were to decline the practice of assessment as a 'remedy', it would risk not being accredited and therefore of being discredited, affecting its image when compared with other academic institutions, which have become ruthless competition. 
\#FunnyNotFunny: Nietzsche foresaw the future - the dawn of the tradesman's era; the triumph of a new evaluative outlook and with it, a new guiding question, the 'question of questions' asked above all the others: 'How many and what class of people will consume this?' (Nietzsche and Kennedy, 2007: 258). Focused on this one exploratory purpose, the tradesman, continued Nietzsche,

instinctively and incessantly employs this mode of valuation and applies it to everything, including the productions of art and science, and of thinkers, scholars, artists [. . .] with respect to everything produced or created he enquires into the supply and demand in order to estimate for himself the value of a thing (Nietzsche and Kennedy, 2007: 258).

The 'thing' at this moment in time is you; and you are constantly required to question and evaluate your worth on the academic market and then, to find ways to increase it. In her book Killing Thinking, sociologist Mary Evans explains that:

From the very first moment when we are told at nursery school that our gluing leaves something to be desired, or that our colouring in is better described as colouring out, we are expected to conform to certain norms and expectations. [...] We test and monitor our weight, our health, our ability to parent and to form lasting relationships. [...] In this context we have to examine the connection between this increasingly anxious culture and university practices (Evans, 2004: 33-34).

Although the idea of evaluating public policies is not new, the evaluation of these policies has developed over the past decade, so much so that it can be interpreted as being internalized, as suggested by the letter in Figure 1. As Evans notes,

since contemporary academics are now routinely assessed by their peers, their students, their Head of Department and whichever external body happens to be visiting the neighbourhood, the career opportunities for the potential assessor are considerable. It is, in fact, a growing sector of higher education and one which offers a deeply rewarding career track for those committed to judgement, and the assessment of what is now known as 'performance' (Evans, 2004: 35).

Anthropologist Cris Shore clarifies that audit, in the academic context is a term meant for quality assessment and is,

of recent origin and was coined by sociologists and anthropologists to describe not so much a type of society, place or people so much as a condition: one shaped by the use of modern techniques and principles of financial audit, but in contexts far removed from the world of financial accountancy. In other words, it refers to contexts in which the techniques and values of accountancy have become a central organizing principle in the governance and management of human conduct and the new kinds of relationships, habits and practices that this is creating (Shore, 2008: 279). 
I am enthusiastically applying for the lectureship. My efficient, independent and collective teaching methods can greatly enhance the reputation of your department. I competently transform lecturing and research into significant learning environments. I prioritise, manage and co-ordinate inclusive action plans to meet coherent and comprehensive targets. Currently my tutoring evaluates complex representations and formations of sexism, heterosexism, racism and class oppression. I train teachers to raise academic achievements by implementing equal opportunities procedures. I am dedicated to promoting stimulating approaches that are relevant to students' aspirations. I optimistically aid multidisciplinary reforms to research and lecturing strategies. I am ethically and morally accountable to giving great educational quality. I offer regular advice, pastoral guidance and curriculum information that develop pragmatic initiatives. Integrating student participation I encourage their academic, personal and social progress.

(Letter of Anblication. UK. 2001)

Figure 1. Letter of application.

Source: Evans (2004)

However, in view of the specificity and diversity of the missions undertaken by universities (initial and continuing training, scientific and technological research, dissemination and valorization of its results, orientation and professional integration, dissemination of culture and scientific and technical information, construction of the European Higher Education and Research Area, international cooperation, etc.), can management control systems actually play the roles defined by statutory, regulatory and normative injunctions? Are the difficulties of implementation such that lessons cannot be learned and the deficiencies identified by auditing cannot be corrected? The issue here, according to Shore, is that 'audit confuses "accountability" with "accountancy" so that "being answerable to the public" is recast in terms of measures of productivity, "economic efficiency" and delivering "value for money", (Shore, 2008: 281). Cris Shore details the scenario in the United Kingdom, where 'recent years have witnessed a dramatic growth in the idea of audit, and faith in its ability to deliver effectiveness and efficiency in all areas of work'. This has extended the use of auditing techniques from companies to almost all public sector institutions in receipt of taxpayers' money which are now obliged to have their financial statements audited by professionally qualified accountants. In the EU, this requirement has been extended to non-financial statements in the form of Environmental, Social and Governance (ESG) auditing. In the case of universities ESG audit reports should guarantee that published statements about such matters as the environmental impact of a university or the employability of its students 'present a true and fair picture'. The purpose of ESG auditing is also to encourage innovation and spread best practice in the rapidly developing field of communicating such information to stakeholders and to ensure good governance. In practice, the work is usually carried out by the 'Big 4' global accountancy firms. Shore is one of many critics who argue that these firms do not practice what they preach, are themselves unaccountable and put their own profits ahead of impartial judgements. Public perceptions of this state of affairs are rising and the result is the 'audit 
expectation gap' (Muhammad, 2012). The growing audit expectation gap may account for some of the opposition to neoliberal matrices of performance among European academics although this hypothesis requires further research. In the meantime, according to Shore the effect is, that on dubious moral or professional authority, 'academics are no longer treated as constitutive members of the university but as its employees, an individualized proletarian workforce that must be "subordinated to the organisational hierarchy of managers, people of whom the 'University' must demand excellence"' (Shore, 2008: 287-289). However, the term 'excellence' often remains nebulous despite the efforts of auditors to develop tools for measuring it.

In the 1980s, the decentralization trend and the economic crisis favouring the development of the idea and practice of evaluation in sectors like public education, had rarely been considered in these terms before. When addressing the issue of evaluation, the discourse of many decision-makers immediately included the use of tools such as indicators, but by observing how these indicators are used to evaluate service projects, it seems this approach contributes to the development of a real culture of evaluation in the administration. There are indeed many 'indicators of actions' and few 'indicators of effects'. My intention here is not to evaluate the relevance of each single indicator, but to develop a broader reflection on their use. Behind this need for evaluation in terms of tools and indicators, the attractiveness (or fascination) that can be perceived for the latter term suggests that decision-makers seem to believe that 'good indicators' could identify reality in a totally objective, rational and indisputable way.

It is as if, in order to evaluate, we could somehow avoid inferring and interpreting from necessarily fragmentary data and we could use quantitative tools and analysis to monitor subjective concepts and constructs such as 'transferable skills', 'relevance', 'entrepreneurship', 'benchmarking' and 'internal audit' (mutual surveillance, colleagues policing their peers) - in short, what is described as the 'technologization of discourse', used to not only monitor and rank entire departments but each individual as well, producing only fear and anxiety. In any case, these policies do not result in creativity, innovation or intellectual engagement. As Shore notes, those scores take 'no account of personal circumstance such as illness, bereavement, or family circumstances' (Shore, 2008: 285). There is also some evidence that the use of performance indicators has different effects depending on the external environment. For example, a small-scale study in Estonia by Turk (2016) found that the use of quantitative performance indicators had positive effects during good times and during restructuring which had the consent of the staff concerned but reduced quality and motivation during times of external crisis. Turk suggests that those who define the objectives need to use more qualitative methods instead of relying solely on quantitative approaches. It is essential for leaders to keep objectives in mind at all times, avoid a one-size-fits-all road to achieving them and avoid the trap of acting as if the mere fact of 'doing something', as though action itself were its own justification and sufficient to satisfy a public which believes in accountability, however ill-informed that belief may be.

However, 'audit culture' and the traditional idea of state power differ in the way the practice of auditing is

implicating all of us in its webs of power: whether it be in the form of annual performance reviews, research assessment exercises, or the competitive ranking of our institutions in The Times Higher Education Supplement league tables of international excellence, we have all bought into the audit culture and allowed it to shape our thinking and our subjectivities (Shore, 2008: 283-290).

Despite all the disadvantages, why do some academics really welcome auditing? Here, Mary Evans offers a disturbing explanation about the acceptance by academics of testing both to assess their students and to be evaluated themselves. They

actually enjoy the process of evaluation and assessment - academics just cannot resist a test, however ridiculous. But one feature of the relationship of academics to tests has become clear in the past twenty years: as academics we cannot avoid assessment and testing, but we have to recognize some of the complexities of our relationship to this process, and the way in which the process can strangle creative and original work (Evans, 2004: 69-70).

This comment applies equally to assessment of students and evaluation of academics' own research efficiency and published output. Basically, because most academics subscribe to values of integrity and self-criticism and aspire to produce quality research, those characteristics 
have become instrumental in prompting compliance. The emphasis on these values and the resulting metrics have transformed the role of the scholar from someone who performs meaningful tasks, such as inspiring their pupils, into a person who is now required to produce a myriad of reports and documents, stating their course objectives, learning outcomes, to list their learning material, and those 'expectations mimic the skills of audit presentation itself: clarity (rather than logic), itemization (rather than connection), bullet points (rather than paragraphs), and simplified organisation (rather than involution or evolution in argument)' (Evans, 2004: 46). As for the issue of 'education rather than training', 'it is far more important', in the current state of affairs, 'that [professors] have produced plans for their courses, bibliographies, outlines of this, that and the other, in short, all the paraphernalia of futile bureaucratization required for assessors who come from on high like emissaries from Kafka's castle' (Shore, 2008: 290). Although some scholars obviously find benefits in this emerging culture of audit (complying with the rules does provide an avenue for rapid promotion and can make for a more comfortable atmosphere in the departmental office after all), the 'audit is not just a series of technical practices: it must also be understood as an idea, a process, and a set of management techniques' (Shore, 2008: 292). The 'ivory tower' in which we research, teach, work and live (given academics' tendency to take additional work home and to work nights, weekends and holidays) is only another misleading conceptual metaphor. This tower is deeply embedded in and subjected to the capitalist system which rules it. Compliance with the audit culture cannot be seen only as a matter of words. After all, in academia, 'words are everything' (Evans, 2004: 151).

\section{Amateurs, intellectuals, experts and the ivory tower}

By nature of its neoliberal societal role as a mirror of the corporate world, the university must be open to promoting mergers and collaborations. Therefore, according to $\mathrm{Sa}^{\prime}$ (2007) there are more and more planned strategies and incentives for faculty networking and interdisciplinarity, at least in research universities. Nevertheless, academics continue to complain in the media that a lot of knowledge remains siloed and that taking an interdisciplinary approach to one's research is damaging to one's career prospects (Dzeng, 2013).

Supporters of interdisciplinarity argue that collaboration and integration are also assets in matters of dynamism, flexibility of organization and management. This flexibility echoes the neoliberal vision of the flexibility of individuals who are encouraged to engage in mobility and to innovate. Ironically, Dzeng argues that the best way of achieving this is to return to the collegiate model of a university espoused by Newman on the basis that this creates informal opportunities for staff from different disciplines to interact far more effectively than structured meetings and management initiatives. In the absence of collegiality, the neoliberal drive for flexibility has instead led to a reform of the scientific career and the end of titled, tenured academic positions. Anthropologist Evthymios Papataxiarchis calls this detitularization 'the international arid zone of post-docs and short contracts' (cited by Mart_nez et al., 2016: 359). This process goes hand in hand with the normalization of temporary appointments that generates insecurity and consequently creates cautiously conformist attitudes from young teachers who are anxious about missing promotions or even losing their jobs. Scholars are weakened by the increasing randomness of career planning and poor job security. The psychological pressure from the ensuing precarity damages young academics' social rights and their social recognition (Tre'pos, 1996).

This is part of a process of departmentalization, the goal of which is the consolidation of services, streamlining administration and supervision, and giving the faculty and researchers a 'better' way of handling both their research and teaching activities, while enabling the university management to measure and audit each department's and each individual's output. But as a recent article from Nature argues, 'some data and anecdotal evidence suggest that scientists do face more hurdles in starting research groups now than did many of their senior colleagues 20-30 years ago'. The article goes on to point out that 'The number of people is at an all-time high, but the number of awards hasn't changed' (Powell, 2016, my emphasis). The article goes on to say that the pressure to publish for both early career and senior scientists, together with the increasing amount of bureaucracy, stifles creativity and produces 'mediocre science'. Peter Higgs, the Nobel Prize-winning physicist who gave his name to the Higgs boson particle, has famously described himself as 'not productive enough for today's academia' (Aitkenhead, 2013). Here, the neoliberal, marketfocused 'hypercompetitive atmosphere' is not improving the field; rather, it is preventing the 
field from reaching its full potential (Powell, 2016).

After all, we all too often hear how 'competition builds character', but the obsession of neoliberalism with competition has created a focus on metrics and created a system full of winners and losers. Beer (2016) makes this connection explicitly, writing that,

Measurement is needed for competition to exist - systems of measurement come hand in hand with what Peck and Tickell refer to as the 'deliberate extension of competitive logics' [. . .] needed to enable competitors to be judged and for hierarchies of winners and losers to be created. Systems of measurement provide the mechanisms by which that competition can be enacted (Beer, 2016: 17)

Rather than having a positive attitude that is shaped by curiosity and the pursuit of knowledge for its own sake as Humboldt expected, the scholar's self-esteem and research agenda, in the neoliberal university, is completely rooted in the sense of having defeated one's peers in a competition. Psychologically, this competition may result in a continuous sense of anxiety and, more significantly, have a corrosive effect on scholars' relationships with their colleagues. Social and cultural analyst Rosalinda Gill suggests in her research on the psychosocial aspects of neoliberalism in academia that "we can reveal the "costs" of neoliberalism which are frequently felt as "insecurity, stress, anxiety and shame"' (Gill, 2009:

18). Similarly, in her analysis focusing on the 'psychic life of neoliberalism', Scharff (2016) reported that the participants to the study shared strong feelings of anxiety, doubt and insecurity.

The university has adopted the idea of usefulness - as an echo of economic utilitarianism, and both in the sense of performance and notoriety - as its central criterion for recognizing its activities, reflecting the business that it has become. The Humboldtian ideal envisaged a university professor as a humanist or a scientist who observes the world as neither a spectator nor an activist working for the betterment of society but solely in order to reveal the truths to be found in the world. To what extent this ideal was ever achieved may be debatable but the contrast with the reality of the present is stark. The neoliberal professor is rather becoming a puppet, devoid of agency, directed by his university, which is in turn obeying the rules of grant providers. Indeed, excellence in research or teaching is increasingly associated with efficiency and profitability. When S_rensen et al. (2016: 16) analysed 'the change in understanding of excellence in the EU's research policy from the Lisbon strategy to the Composite Indicator for Scientific and Technological Research Excellence', they described the new idea of excellence as 'very broad, fuzzy and umbrellalike' but had been 'narrowed down into four concrete measurements in the final version of the composite indicator: the share of highly cited publications, the number of top scientific universities and public research organizations in a country, top patent applications and ERC grants' (S_rensen et al., 2016: 16). Over the last 15 years, the understanding of excellence in the research policy of the EU has changed significantly; this change corresponds to the distinction makes between 'research excellence' and a broader concept of 'scientific excellence' in many different ways. The Lisbon strategy focused on excellence in the broad sense of the word whereas the new indicator represents a narrower, more focused or - as some critics might say - reductionist view of excellence.

Science must not only be useful to society, but its usefulness should also be proportional to the investments that society has made in it. Moreover, this usefulness is defined by the development of increasingly narrow skills in increasingly specialized areas of activity. Therefore, this vision defines academics primarily as specialists whose job position is legitimated solely in relation to the usefulness of their speciality. This model considers the university to be a set of specialities, and would form a whole for which only the generic appellation of 'sciences' would ensure consistency, constituting specialized areas relatively impermeable to each other. Despite the use of buzzwords such as interdisciplinarity and collaboration in official statements, the speciality per se has become one of the constituent parts of university life. Furthermore, the idea of 'a speciality' obviously goes hand in hand with a certain number of 'specialists'. It is no coincidence that the entrepreneurial university claims the concept of expertise. The figure of the expert, in fact, is central to the discourse of management from the 1990s, and among the most valued next to that of the manager and the project manager. Therefore, the university professor must now be a specialist in this managerial mode. This means that in the new ideal university, there are no more distracted scholars, old mavericks with their lost esoteric knowledge, and most especially no more 'bossy' professors, those inaccessible despots who more or less enlightened their students but 
were dreaded by them.

This model fails to answer a fundamental question: why would 'being an amateur' in academia be so problematic? The importance of curiosity for its own sake in the Humboldtian model created a class of professional amateurs whose value was praised by Edward Said, the founder of postcolonial studies. Edward Said actually celebrated the concept of amateurism, calling it

the desire to be moved not by profit or reward, but by love for an unquenchable interest in the larger picture, in making connections across lines and barriers, in refusing to be tied down to a specialty, in caring for ideas and values despite the restrictions of a profession (Said, 1994: 76).

Amateurs must inherently be anti-instrumental and unconcerned for rewards or status. Expertise, on the contrary, is marketable, and therefore profitable.

In addition to supplanting and marginalizing the amateur, the culture of expertise creates tension with another of academia's most important figures: the intellectual. If the recognition of expertise is certainly rewarding to the scholar, so too being identified as an intellectual. While the intellectual and the expert are both committed to intervening for the common good, there is an important distinction in their roles that frequently places the two at odds. The expert's goal is to increase the value of the university-business in the spirit of the ideology of the dominant discourse, while the intellectual's pursuit of truth and continuation of the university's values and Humboldtian humanist tradition both generates prestige for the university and allows the institution to claim the moral high ground. This important distinction creates a tension between the expert and the intellectual, even though they both pursue the improvement of society at large. The intellectual's caution, critical distance and emphasis on the slow maturation of ideas are traditional characteristics of a university. However, they have also become synonymous with the some of the greatest vices disparaged by the neoliberal world: slowness, inefficiency or even indifference to the 'real' needs of the world. These qualities, which once made the university both an engine of innovation and the site of important moral conversations, have now become emblematic of the so-called ivory tower that many neoliberal forces seek to bury in the past.

\section{Concluding remarks}

While the process of neoliberalization was initially forced on European universities by political authorities, as exemplified by the Bologna process, it now seems that university directorates voluntarily impose the same undiscerning, unreflective leap towards narrowly utilitarian knowledge dominated by market forces and inclinations to meet the interests of the enterprise. However, it would be equally unreflective to not take the labour market into account when discussing university reform; it is perfectly reasonable to create new educational channels at the university to better meet the needs of certain work positions.

The challenge that universities must navigate if they are to be the engines of innovation and the sites of moral discussions is to strike a balance between meeting these demands and preserving fields of study like Oriental languages, classical philology and all the other disciplines that serve as fundamental pillars for teaching thinking skills. While education is indeed a public good, it is not the railway system. Rather, education produces particular products - knowledge for its own sake, as Humboldt recognized, and knowledge dissemination, as Newman emphasized. The key task for education's would-be reformers is to preserve the traditional role of the university as a site that encourages debate to help us build the society that we want to build, while still maintaining a fundamental balance between the elitist and generalist sectors and sectors that are more closely aligned with the needs of enterprises. The point here is to avoid the rising dualism between these two groups, which is likely to create a division that will have unforeseeable consequences. It is in this sense that the university world is polarized. On the one hand, some are rather satisfied with the trend of writing a lot about research themes of immediate use to the economy and deepening little. On the other hand, as this trend is supported by governments and directorates as well as guided by the European Framework Programmes for Research and Innovation, those who oppose it feel powerless. The fate of universities is now out of their own hands and has been placed in the hands of society's decision-makers, which does not mean society as a whole. Serving the interest of this minority will bring about the end of the university as it has been understood in Europe since the early 19th century. 
The future of the university, like the future of railways, the Post Office and social security, requires far-reaching political choices. Progress lies not only in quantifiable, measurable things, as some expert economists who manage universities would have you believe. The question of the future of the university in fact raises the question of what kind of society we wish to build. That society goes hand in hand with culture, and culture goes hand in hand with knowledge. A humanity of goodness is directly dependent on the importance we will allocate to knowledge and, by extension, to science. Since the Middle Ages, the university has unceasingly generated culture, and has therefore, in spite of its more or less submissive connections with different power structures, never stopped being a transmitter of innovative, original and emancipatory knowledge. In the 19th century, it became the symbol of scientific advances that had the capacity to free humankind both intellectually and spiritually, and to improve the material conditions of their existence. Utopia? If we contemplate what it has become by the end of the next century, certainly. The reduced mobilization capacity of the academic and scientific sector has undoubtedly played a role in the disintegration of its utopic aims. But a path to a utopic university is still possible if those who belong in it transcend the present divisions, and if the atomization of individuals and disciplines moves towards a rediscovery of what makes the specificity of the alma mater, namely its unifying purpose in terms of knowledge. Whether we can reverse this trend remains an open question. It will require an enormous collective effort, but we might be short of an alternative.

Declaration of conflicting interests

The author declared no potential conflicts of interest with respect to the research, authorship, and/or publication of this article.

Funding

European Commission (Brussels) 2013-10-01 to 2017-09-30|GRANT_NUMBER: 607279

ORCID iD

Ana Tomicic http://orcid.org/0000-0002-2504-4945

\section{References}

Aitkenhead D (2013) Peter Higgs: I wouldn't be productive enough for today's academic system. The Guardian, 6 December, https://www.theguardian.com/science/2013/dec/06/peter-higgs-boson-aca demic-system (accessed 10 October 2018).

Alain R (1995) Les re'volutions de l'universite': essai sur la modernisation de la culture [The revolutions of the university: essays on the modernisation of culture]. Paris: Calmann.

Amsler S and Bolsmann C (2012) University ranking as social exclusion. British Journal of Sociology of Education 33(2): 283-301.

Anderson R (2010a) European Universities from the Enlightenment to 1914. Oxford: Oxford

University Press.

Anderson R (2010b) The 'Idea of a University' Today. History and Policy. Available at: http://www. historyandpolicy.org/policy-papers/papers/the-idea-of-a-university-today (accessed 17

October 2016).

Beer D (2016) Metric Power. Basingstoke: Palgrave Macmillan.

Berchem T (2004) Tradition et progre 's, la mission de l'universite' [Tradition and progress, the mission of the university] (Vol. 176). Paris: Fayard.

Bologna Declaration (1999) Joint declaration of the European Ministers of Education convened in Bologna on the 19th of June 1999. Bologna. Available at: http://www.magna-charta.org/resources/ files/BOLOGNA_DECLARATION.pdf (accessed 23 February 2017).

Charle C and Soulie' C (2007) Les ravages de la 'modernisation' universitaire [The ravages of 'modernisation' for the university]. Parution (livre collectif), Paris: E' d. Syllepse.

Choat S (2017) Tuition fees and the neoliberal university: Responding to the 2017 Higher Education and Research Act. Renewal 25(3-4). Available at: http://www.renewal.org.uk/articles/tuition-feesandthe-neoliberal-university-responding-to-the-2017-higher-ed (accessed 23 February 2017)

Tomicic 19

Cochinaux P and de Woot P (1995) Moving Towards a Learning Society: Ba CRE-ERT Forum Report on European Education. CRE. Belgium: European Round Table'of Industrialists, Brussels; Switzerland: Association of European Universities.

Dzeng E (2013) How to inspire interdisciplinarity: lessons from the collegiate system. The Guardian, 15 March, https://www.theguardian.com/higher-education-network/blog/2013/mar/15/interdisciplin ary-academic-universities-research (accessed 23 February 2017). 
ETUC, UNICE, CEEP, et al. (2006) Framework of actions for the lifelong development of competencies and qualifications. http://erc-online.eu/wp-content/uploads/2014/04/2007-01090-EN.pdf (accessed 23 February 2017).

European Commission (2019) The Bologna Process and the European Higher Education Area Education and Training. Available at: https://ec.europa.eu/education/policies/higher-education/ bologna-process-and-european-higher-education-area_en (accessed 23 February 2017).

European Economic and Social Committee (2007) OPINION of the European Economic and Social Committee on Business potential, especially of SMEs (Lisbon Strategy) (Own-initiative Opinion). Available at: http://edz.bib.uni-mannheim.de/edz/doku/wsa/2007/ces-2007-0982-en.pdf (accessed 20 March 2017).

European Parliament Directorate General for Internal Policies Policy Department B Structural and Cohesion Policies (2015) University Quality Indicators: A Critical Assessment. Strasbourg: European Parliament.

Evans M (2004) Killing Thinking: Death of the University. London, UK: Bloomsbury Publishing. Finlayson G and Hayward D (n.d.) Education towards Heteronomy: A Critical Analysis of the Reform of UK Universities since 1978. Brighton: University of Sussex. Available at: http://users.sussex.ac. uk/_jgf21/eth final version.pdf

Fr_lich N, Coate K, Mignot-Gerard S, et al. (2010) Einheit von Forschung und Lehre: Implications for state funding of universities. Higher Education Policy 23(2): 195-211.

Gelauff G, Grilo I and Lejour A (2008) Subsidiary and Economic Reform in Europe. Berlin: Springer Gill R (2009) Breaking the silence: The hidden injuries of neo-liberal academia. In Secrecy and Silence in the Research Process: Feminist Reflections. Abingdon, United Kingdom: Routledge, pp. 228-244. Goffman E (2009) Stigma: Notes on the Management of Spoiled Identity. Simon and Schuster. New York City, United States: Touchstone, p. 127.

Gueissaz A (1999) Les mondes universitaires et leur informatique: pratiques de rationalisation [University world and their digitalisation: the practice of rationalisation]. CNRS, Paris, France. Hirsch D (2002) Report on the OECD/US Forum on Trade in Educational Services. OECD, Washington, DC .

KAIM (2000) Internationales Marketing für r den Bildungsund Forschungsstandort Deutschland. Berlin: KAIM.

Krajina J and Krajina AT (2014) The implementation of the Bologna Process in Republic of Croatia. In Economy of Eastern Croatia Yesterday, Today, Tomorrow, vol. 3, pp.169-175. Josip Juraj Strossmayer University of Osijek, Faculty of Economics, Croatia

Lund R (2018) The social organisation of boasting in the neoliberal university. Gender and Education 1-20. Mart_nez F, Ivancheva M, Simoni V, et al. (2016) Rethinking Euro-anthropology: part three. Early career scholars' forum. Social Anthropology 24(3): 353-379.

Muhammad P (2012) Audit Expectation Gap: An Empirical Review of the Literature. Academia.edu. Kaduna State University, NIgeria

Newman J (1845) The Idea of a University Defined and Illustrated: I. In Nine Discourses Delivered to the Catholics of Dublin. Dublin: Guttenberg Project. Available at: https://www.gutenberg.org/ ebooks/24526 (accessed 20 January 2019).

Nietzsche F and Kennedy JM (2007) The Dawn of Day. North Chelmsford, USA: Courier Corporation. Powell K (2016) Young, talented and fed-up: scientists tell their stories. Nature 538(7626): 446-449.

20 Policy Futures in Education 0(0)

Pritchard R (2004) Humboldtian values in a changing world: Staff and students in German universities. Oxford Review of Education 30(4): 509-528.

Ray E (1997) Can a college education really be reduced to numbers?

Readings B (1996) The University in Ruins. Cambridge, United States: Harvard University Press.

Sa' C (2007) 'Interdisciplinary strategies' in U.S. research universities. Higher Education 55(5): 537-552.

Said E (1994) Professionals and Amateurs: Representations of the Intellectuals. London: Vintage, p. 62.

Samarasekera I (2007) Rising up against rankings. Higher Education 2. Available at: https://www. insidehighered.com/views/2007/04/02/rising-against-rankings (accessed 23 February 2017).

Saunders D (2010) Neoliberal ideology and public higher education in the United States. Journal for Critical Education Policy Studies 8(1): 42-67.

Scharff C (2016) The psychic life of neoliberalism: Mapping the contours of entrepreneurial subjectivity. Theory, Culture \& Society 33(6): 107-122.

Serrano-Velarde K and Stensaker B (2010) Bologna - realising old or new ideals of quality? Higher Education Policy 23(2): 213-226.

Shore C (2008) Audit culture and illiberal governance: Universities and the politics of accountability. Anthropological Theory 8(3): 278-298.

S_rensen MP, Bloch C and Young M (2016) Excellence in the knowledge-based economy: from scientific to research excellence. European Journal of Higher Education 6(3): 217-236.

Sosteric M, Gismondi M and Ratkovic G (1998) The university, accountability, and market discipline in the late 1990s. Electronic Journal of Sociology 3(3): 1-16.

Tre'pos JY (1996) La sociologie de l'expertise [The sociology of expertise], PUF, Paris, France

Tu“ rk K (2016) Performance management of academic staff and its effectiveness to teaching and 
research - based on the example of Estonian universities. Trames: Journal of the Humanities and Social Sciences 20(1): 17.

Tworek H (2013) The real reason the humanities are 'in crisis'. The Atlantic, https://www.theatlantic. com/education/archive/2013/12/the-real-reason-the-humanities-are-in-crisis/282441/ DEC 18, 2013 Wilson J (2012) Consuming Higher Education. London: Continuum.

Ana Tomicic is a Social Anthropologist and $\mathrm{PhD}$ in Social Representations and Communication. In the thesis, she addresses issues surrounding the neoliberalization of European academia, examining the ideological support of the current change within the university. Her primary research interests revolve around the sociology of knowledge, the social construction of knowledge and the transformation of expert into lay knowledge, in particular in the field of economics. Her secondary research interests include postcolonial theory, postsocialism and utopias. 